\title{
Modeling and optimization of boiler combustion system in power station
}

\author{
Jiaying Zhang ${ }^{1}$, Xuhan Zhang $^{1}$, Zhe Wang ${ }^{1}$ \\ ${ }^{1}$ Power college of Inner Mongolia University of Technology, China
}

\begin{abstract}
This paper studies on researching the method of reducing NOx production and coal consumption of coal-fired power station boiler. It takes a power plant $600 \mathrm{MW}$ subcritical boiler as the research object, from the power plant Supervisory Information System (SIS) it gets the historical operation data as experimental data. Based on GA-GRNN (generalized regression neural network based on genetic optimization), a predictive model of boiler combustion system with 39 variables such as inlet and output of coal consumption and NOx production was established. Finally, coal consumption and NOx production were optimized based on the neural network model of boiler combustion system. In this paper, 29 adjustable thermal parameters of boiler combustion system model input are selected as optimization variables and the improved NSGA-II (non-dominated sorting genetic algorithm) is used to optimize multiple objective variables. The optimization study was carried out under the actual operating condition of 349.21 MW. After optimization, the coal consumption of power supply was reduced by $5.67 \%$ and the NOx production was reduced by $50 \%$. Therefore, the optimization results provide guidance for adjusting the combustion of utility boilers.
\end{abstract}

\section{Introduction}

Entering the 21st century, the installed power capacity in China has developed rapidly. According to the statistics by the end of 2016, China's total installed capacity of full-calibre power generation is 1.65 billion $\mathrm{kw}$, ranking the first in the world. Among them, the installed capacity of thermal power generating units is 1.05 billion $\mathrm{kw}$, which is $63.6 \%$ of the total domestic power generation ${ }^{[1]}$.

Based on the current status of thermal power generation, power plants need to improve the efficiency of generating units, as far as possible to make the work of generating units tend to the optimal working conditions and reduce coal consumption.

This paper is based on the historical operation data of a 600MW subcritical boiler in a power plant, the prediction model of Generalized regression neural networks (GA-GRNN) based on genetic optimization is obtained, by using generalized regression neural network (GRNN) to establish a combustion system prediction model, and utilize genetic algorithm (GA) to optimize the SPREAD value of the extended constant of the radial basis function of the neural network mode. Based on this model, the advanced non dominated sorting genetic algorithm (NSGA-II) is adjustable for multi-objective optimization of boiler operation parameters ${ }^{[2,3]}$.

\section{Boiler combustion system modeling process}

\subsection{Boiler combustion system model structure}

The process of power station boiler combustion is very complicated, so it can not be described with precise mathematical expression. In this paper, the black box model of boiler combustion system is established by using GA-GRNN based on the historical operation data of power plant. Neural network model of input variable selection for: total air volume, the total amount of coal, gross primary air volume, air volume of air supply fan, blower inlet temperature, generator active power, differential pressure between bellows and furnace, instantaneous coal capacity of coal feeder(A B C D E F), the SOFA layer 1 angle of burn

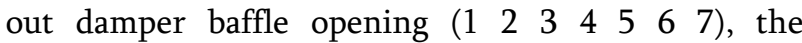
secondary air damper baffle opening (AA AB BC CD DE EF FF), OFA damper opening, $E$ export wind powder grinding temperature, E grinding inlet air flow, $E$ export wind powder grinding pressure, burner swing angle, circumferential damper opening $(\mathrm{A}, \mathrm{B}, \mathrm{C}, \mathrm{D}, \mathrm{E}$, F), coal quality. A total of 39 variables were used to 
characterize the effects on coal consumption and NOx production of boiler combustion system ${ }^{[4-6]}$.

\subsection{GA-GRNN establishment and forecast of network model}

In this paper, the historical operation data of a power station boiler is taken as the experimental data, and the steady-state data under the operating conditions of $347^{\sim} 549 \mathrm{MW}$ interval is taken as the experimental data to establish the boiler combustion system model. A total of 299 data samples were selected in the experiment. Among them, 209 data samples were taken as the modeling training set, and 90 data samples as the test set. The prediction model of boiler combustion system is established by using GRNN neural network. The procedure for creating GRNN in MATLAB is shown below net=newgrnn $(\mathrm{P}, \mathrm{T}, \mathrm{SPREAD})$

$\mathrm{P}$ : group $\mathrm{Q}$ input vector composed of $\mathrm{R} \times \mathrm{Q}$ dimensional matrix

$\mathrm{T}$ : group $\mathrm{Q}$ object vectors composed of $\mathrm{S} \times \mathrm{Q}$ dimensional matrix

SPREAD: The extension constant of the radial basis function

For GRNN, when the input and output sample data for training are determined, the structure and weight of the network are also determined. In order to establish the prediction model with GRNN, the first task is to determine the value of SPREAD constant ${ }^{[7]}$. In this paper, the basic genetic algorithm is used to realize the optimization of SPREAD value of GRNN extension constant, and finally the GA-GRNN prediction model is obtained. The parameters of the genetic algorithm are set as: population size $\mathrm{M}=30$, crossover probability $\mathrm{Pc}=0.75$, mutation probability $\mathrm{Pm}=0.15$, and genetic termination algebra $\mathrm{T}=150^{[8]}$.

Through simulation experiment, the evolutionary algebraic curve of the genetically optimized GRNN is shown in Fig1. When evolution algebra $\mathrm{T}=3$, fitness function, that is, the mean square error of the test sample reaches the minimum, the values of $\mathrm{MSE}=4.485 \times 10-3$, at this point, the optimal SPREAD constant of GRNN is 0.23 , the predicted value curve and the real value curve of NOx production were tested on GA-GRNN network with test samples, as shown in Fig2, the average relative error of the predicted results is 0.038 , the predicted value curve and the real value curve of coal consumption are shown in Fig3 and the average relative error of the predicted results is $0.075^{[9]}$.

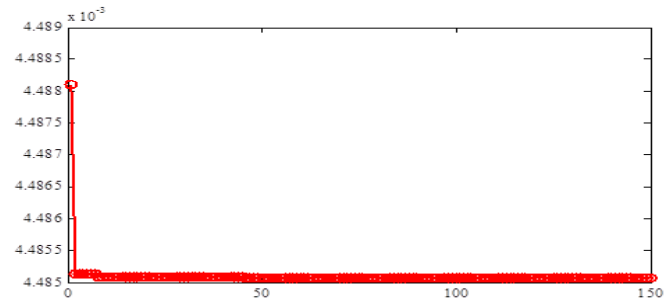

Fig 1. Genetic algorithm optimizes GRNN's evolution algebra and fitness curve

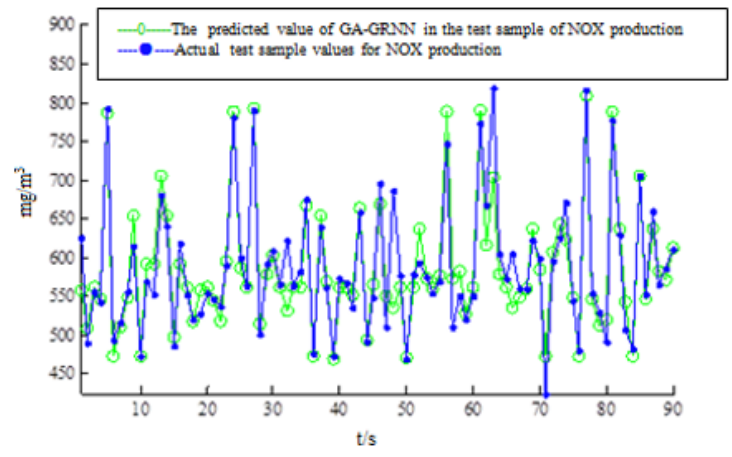

Fig 2. Curve of the predicted and actual value of GA-GRNN model for NOx Production

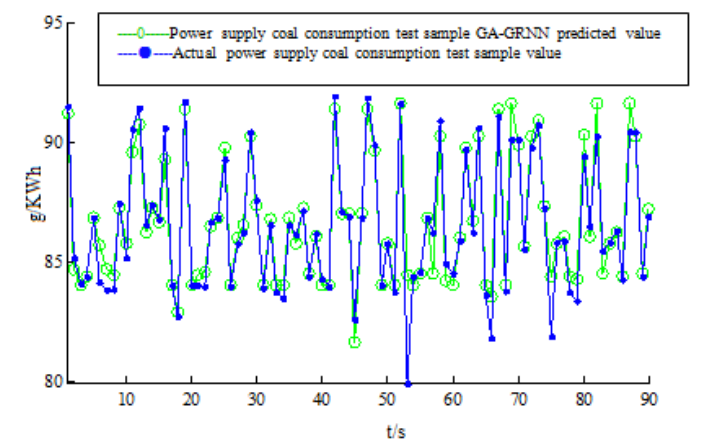

Fig 3. Curve of the predicted and actual value of GAGRNN model for coal consumption

\section{Combustion optimization process of power station boiler}

\subsection{Multi-objective optimization model for $600 \mathrm{MW}$ subcritical units}

Based on the principle of minimizing power supply coal consumption and NOx production, the objective function of multi-objective optimization for boiler combustion is constructed by combining the constraint conditions, as shown in equation $(1)^{[10]}$.

$$
\begin{aligned}
& \min \left\{\text { Ccons, } N O_{x}\right\} \\
& \text { s.t }\left\{\begin{array}{l}
\text { Ccons }=f\left(M_{v}, D_{v}\right) \\
N O_{x}=f\left(M_{v}, D_{v}\right) \\
{\left[M_{v}\right]_{\min } \leq M_{v} \leq\left[M_{v}\right]_{\max }}
\end{array}\right.
\end{aligned}
$$

In the above equation, Ccons, $N O x$ represents the two optimization objectives of the boiler combustion system, $f$ represents predicting coal consumption and the network model for $N O x . M V$ represents a vector composed of adjustable parameters such as one or two 
damper openings, $D_{V}$ represents the vector composed of coal and other unadjustable parameters. $[M V]_{\min }$ and $\left[M_{V}\right]_{\max }$ are the constraint range of adjustable parameters.

\subsection{Selection of optimization variables for combustion of power station boiler}

In this paper, some adjustable parameters are selected as variables to be optimized and other input variables are selected as constants for direct input according to the existing related research and the field operation data obtained. In total, 29 variables to be optimized are selected, $\mathrm{x} 1^{\sim} \times 7$ is $1 \sim 7$ floor 1 Angle SOFA air door opening, $x 8^{\sim} \times 14$ is the opening degree of secondary air damper of $\mathrm{AA} A B \mathrm{BC} C D \mathrm{DE} E \mathrm{EF} F$ F layer, $\mathrm{x} 15 \sim \mathrm{x} 20$ represents the instantaneous coal feeding amount of $A$, B, C, D, E and F coal mills, $x 21^{\sim} x 26$ is A, B, C, D, E and $\mathrm{F}$ ambient wind volume, $\mathrm{x} 27$ is OFA wind air volume, $x 28$ is burner swing angle, $x 29$ is differential pressure of hearth bellows. In the actual operation of power station boiler, the operation operator of the power station can adjust the combustion by adjusting the opening of the damper in DCS system such as the speed of coal feeding machine and the swinging angle of burner ${ }^{[11]}$.

\subsection{Optimization of power station boiler combustion}

The actual working condition of $349.21 \mathrm{MW}$ is selected for optimization, the optimization method uses the improved non-dominant genetic algorithm(NSGA- II), and through MATLAB platform implementation, the flow chart of optimization algorithm is shown in Fig4. The advanced NSGA- II parameters are set as follows: the population size is 100 , the tournament selection operator; the weighted average crossover algorithm; crossover probability is 0.85 ; the constraint adaptive mutation algorithm has a mutation probability of 0.25 ; the optimal front-end individual coefficient is 0.5 and the maximum number of iterations is $1000^{[12,13]}$.

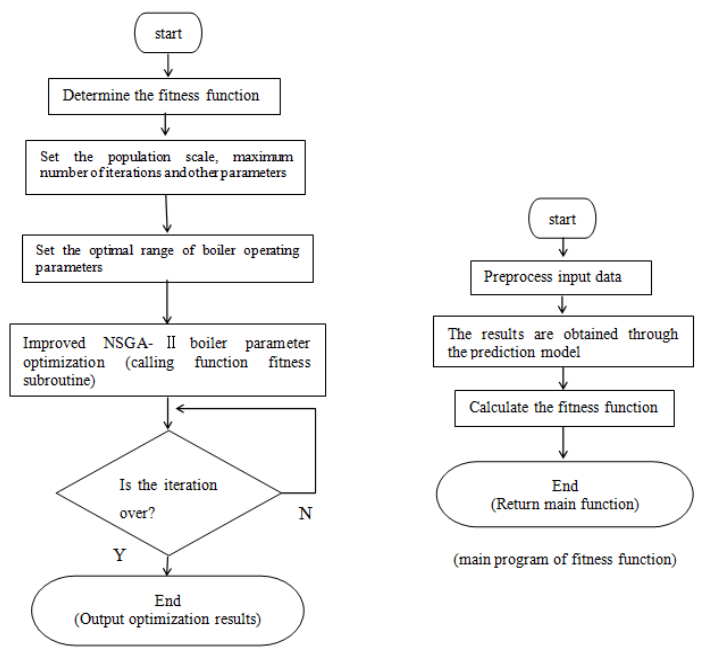

Fig4. Flow chart of the optimization algorithm

\subsection{Analysis of optimization results}

After optimization, the optimization results are shown in Fig5. In the Fig5, pareto solution constitutes the optimal front-end curve of Pareto, and the candidate solution is the dominant solution set formed by other different front-ends. It can be seen from the optimal front-end curve, there is a linear correlation between coal consumption and NOx production. With the reduction of power supply coal consumption, NOx production gradually increases. The improved NSGAII algorithm takes into account two optimization objectives at the same time to obtain feasible solutions of simultaneously reducing coal consumption and $\mathrm{NOx}$ production. The power station operator can set operation parameters with the optimized adjustable value in DCS in order to improve the boiler operation efficiency ${ }^{[14]}$.

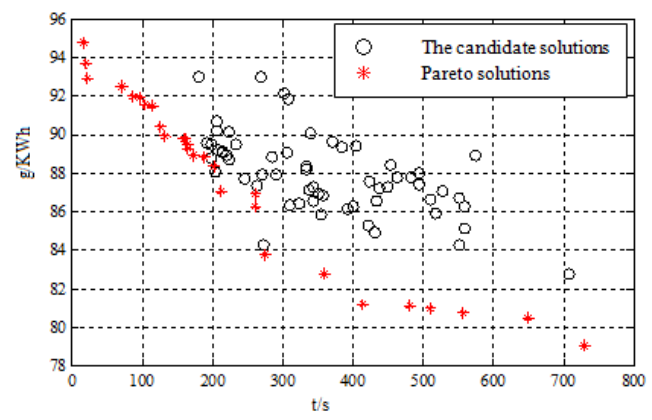

Fig5. Pareto solution and candidate solution for condition 1

The working condition of $349.21 \mathrm{MW}$ is four coal mills in the middle working simultaneously, the upper and lower two coal mills stop working. At the end of the optimization process, a group of results obtained from the optimal solution set of Pareto were selected for analysis, table 1 shows the values of the two targets before and after optimization. After optimization, the power supply coal consumption is decreased by $4.88 \mathrm{~g} / \mathrm{kWh}$, with a decreasing range of 
$5.67 \%$ and the production is decreased by $415.8 \mathrm{mg} / \mathrm{m}^{3}$, with a decreasing range of $50 \%$. The values of optimization variables before and after optimization are shown in table2, table3, table4 and table5. From the change of the secondary damper opening, the optimized secondary damper opening is from bottom to top and the opening of the damper at both ends increases, the opening of the damper of the intermediate damper decreases, and eventually the "waist air distribution" mode is formed. Such distribution method will weaken the rotating intensity of flue gas in the main combustion area in the middle of the furnace, which can effectively absorb the hightemperature flue gas generated by the upper and lower burners. It also increases the travel time and retention time of flue gas in furnace, so as to weaken the rotating residual at the outlet of the furnace, promote the uniformity of temperature field and velocity field at the outlet of the furnace, reduce the temperature deviation of flue gas at the outlet of the furnace, reduce the carbon content of flying ash and increase the burnout rate of coal powder correspondingly. In addition, with the characteristics of two large middle small air distribution, because of the large upper auxiliary air volume, the flame can be effectively compressed and the gas rotation speed can be restrained. It not only controls the position of the flame, but also promotes the burning of coal powder, a large amount of auxiliary air below can effectively hold the flame, prevent the coal powder from being separated from the flame and flush to the cold ash bucket, thus increasing the carbon content of the slag [15].

It can be seen from the optimized opening of exhaust air damper, the opening of exhaust air damper in the middle of the furnace greatly increases, making the temperature in the center of the furnace drop, in addition, the secondary air volume in the main combustion zone decreases, which leads to the lack of oxygen in the environment, and finally forms a relatively strong reducing atmosphere, which effectively inhibits the generation of NOx, thus greatly reducing its concentration. In addition, the opening degree of the top exhaust air (OFA) is increased. The coal powder that is not completely burned is spiraled upward with the air flow. When the coal powder is mixed with the top exhaust air, the coal powder is promoted to be burnt out.

Table 1. Values before and after Optimization Target

\begin{tabular}{|c|c|c|c|c|}
\hline $\begin{array}{c}\text { Optimal } \\
\text { working } \\
\text { condition }\end{array}$ & $\begin{array}{c}\text { Optimization } \\
\text { goal }\end{array}$ & $\begin{array}{c}\text { Boiler } \\
\text { load }\end{array}$ & $\begin{array}{c}\text { NOx } \\
\text { generation }\end{array}$ & $\begin{array}{c}\text { The power } \\
\text { supply coal } \\
\text { consumption }\end{array}$ \\
\cline { 3 - 5 } & $\mathrm{MW}$ & $\mathrm{mg} / \mathrm{m}^{3}$ & $\mathrm{~g} / \mathrm{KWh}$ \\
\hline
\end{tabular}

\begin{tabular}{|c|c|c|c|c|}
\hline \multirow{3}{*}{$\begin{array}{l}\text { Working } \\
\text { condition }\end{array}$} & $\begin{array}{c}\text { Before } \\
\text { optimization }\end{array}$ & \multirow{3}{*}{349.21} & 831.37 & 86.09 \\
\hline & $\begin{array}{c}\text { After } \\
\text { optimization }\end{array}$ & & 415.57 & 81.21 \\
\hline & $\begin{array}{c}\text { After } \\
\text { optimization }\end{array}$ & & 415.57 & 81.21 \\
\hline
\end{tabular}

Table 2. Values before and after Optimization Variables in Working Condition 349.21MW

\begin{tabular}{|c|c|c|c|c|c|c|c|c|}
\hline \multirow{7}{*}{$\begin{array}{c}\text { Optimiza } \\
\text {-tion } \\
\text { variables }\end{array}$} & \multicolumn{6}{|c|}{$\begin{array}{c}\text { Instantaneous coal capacity of } \\
\text { coal feeder, t/h }\end{array}$} & $\begin{array}{l}\text { Burner } \\
\text { Angle }\end{array}$ & $\begin{array}{c}\text { Chamber } \\
\text { differentia } \\
\text { l pressure }\end{array}$ \\
\cline { 2 - 8 } & $\mathrm{A}$ & $\mathrm{B}$ & $\mathrm{C}$ & $\mathrm{D}$ & $\mathrm{E}$ & $\mathrm{F}$ & $\circ$ & $\mathrm{KPa}$ \\
\hline $\begin{array}{c}\text { Before } \\
\text { optimiza } \\
\text {-tion }\end{array}$ & 0.0 & 41.39 & 44.37 & 43.43 & 38.40 & 0.00 & 55.00 & 532.56 \\
\hline $\begin{array}{c}\text { After } \\
\text { optimiza } \\
\text {-tion }\end{array}$ & 0.0 & 45.89 & 40.00 & 51.12 & 36.43 & 0.00 & 51.84 & 531.45 \\
\hline
\end{tabular}

Table 3. Values before and after Optimization Variables in Working Condition 349.21MW

\begin{tabular}{|c|c|c|c|c|c|c|}
\hline \multicolumn{7}{|c|}{ Secondary air damper opening, \% } \\
\hline $\mathrm{AA}$ & $\mathrm{AB}$ & $\mathrm{BC}$ & $\mathrm{CD}$ & $\mathrm{DE}$ & $\mathrm{EF}$ & $\mathrm{FF}$ \\
\hline 34.22 & 59.00 & 47.77 & 45.94 & 98.07 & 67.99 & 17.68 \\
\hline 87.69 & 46.01 & 52.17 & 25.23 & 23.40 & 50.87 & 54.04 \\
\hline
\end{tabular}

Table 4. Values before and after Optimization Variables in Working Condition 349.21MW

\begin{tabular}{|c|c|c|c|c|c|}
\hline \multicolumn{6}{|c|}{ Circumferential wind damper opening, \% } \\
\hline A & B & C & D & E & F \\
\hline 12.53 & 33.07 & 32.46 & 26.52 & 31.82 & 15.06 \\
\hline 28.49 & 34.38 & 25.84 & 35.18 & 37.84 & 16.17 \\
\hline
\end{tabular}

Table 5. Values before and after Optimization Variables in Working Condition 349.21MW

\begin{tabular}{|c|c|c|c|c|c|c|c|}
\hline \multicolumn{7}{|c|}{ Exhaust air damper opening, \% } & $\begin{array}{c}\text { OFA damper } \\
\text { opening\% }\end{array}$ \\
\hline & 2 & 3 & 4 & 5 & 6 & 7 & \\
\hline 0.58 & 85.64 & 84.40 & 0.50 & 0.50 & 0.55 & 0.46 & 32.80 \\
\hline 0.55 & 81.65 & 65.96 & 80.02 & 0.53 & 0.56 & 0.44 & 47.90 \\
\hline
\end{tabular}

\section{4 conclusion}

Aiming at the problem of boiler combustion system modeling and optimization, based on the historical operation data, this paper proposes to use GRNN to establish combustion system prediction model and uses genetic algorithm to optimize the expansion constants of the network model to get the GA-GRNN prediction model. Test data is used to test the model 
respectively, and the results verify the validity of the GA-GRNN network model. The improved NSGA-II (non-dominated sorting genetic algorithm) is used to optimize multiple objective variables. The results show that both coal consumption and NOx production are improved. If the results obtained from the optimization process are applied to DCS system to guide the setting of boiler combustion operation parameters, it will have a positive guiding significance for the future research and practical application of boiler combustion optimization.

\section{Acknowledgment}

Project 2016MS0621 supported by Inner Mongolia Natural Science Foundation

\section{References}

1. Qingyu Shang,"Current status and development trend of pulverized coal industrial boilers in China", Coal Science and Technology, vol. 01, pp. 201-206, April 2016.

2. Dayong Song, Jiawei Zhang, Wu Ju, et al. "Comprehensive Treatment of NOx Emissions and Unit Economics of 300MW Subcritical Boiler", Northeast Electric Power Technology, pp. 19-22, March 2016.

3. Emission standard of air pollutants for coal-fired boilers: GB 13271-2014[S].

4. Emission standard of air pollutants for thermal power plants: GB 132232011[S].

5. Lijing $\mathrm{Gu}$, Yonghua $\mathrm{Li}, \mathrm{Lu} \mathrm{Li}$, "Mixed model prediction of combust-ion optimization for utility boilers". Proceedings of the CSEE, vol. 09, pp. 231233, April 2015.

6. Dongfeng Wang, Qian Liu, Jun Han, et al, "Optimization of Utility Boiler Combustion Based on Big Data Driven Case Matching”, Journal of Instrumental and Instrumental, vol. 02, pp. 420-428, April 2016.

7. Lingxuan Yin, Mingchun Wang, Qiang Shang, Optimization of Utility Boiler Combustion Based on Support Vector Machines and Particle Swarm Optimization", Journal of Boiler Technology, pp. 13-17, April2014.

8. Jinchao Huang, "Classification and identification of mint plants based on generalized regression neural network",Middle Tangshan Normal University Journal, vol.12, pp. 38-41, July2009.

9. Ye Jian,"Multi-objective optimization design of slurry pump based on radial basis neural network and NSGA_ algorithm", Jiangsu University, July2016.

10. Ilamathi $\mathrm{P}$, Selladurai $\mathrm{V}$, Balamurugan $\mathrm{K}$, "Modeling and Optimization of Unburned Carbon in Coal-Fired Boiler Using Artificial Neural Network and Genetic Algorithm", Journal of Energy Resources Technology, vol.03, pp. 364-392, June2013.

11. Li G, Niu P, "Combustion optimization of a coalfired boiler with double linear fast learning network", Soft Computing, vol.19, pp. 149156,November 2015.

12. P Ilamathi, V Selladurai, K Balamurugan, "ANNAGA approach for predictive modeling and optimization of NOx emission in a tangentially fired boiler",Clean Technologies and Environmental Policy, 125-131,November 2013.

13. Feng Shi, Hui Wang, Fei Hu, Lei Yu, "30 cases of MATLAB intelligent algorithm",Beijing University of Aeronautics and Astronautics Press, May2011.

14. Deming Lei,Xinping Yan,"Multi-objective intelligent optimization algorithm and its application",Science Press, December2009.

15. Guangming Zhu, "Inferior Coal Blending and Optimized Combustion Technology for Power Plant Boilers", China Electric Power Press, vol.27, pp. 162-169, October 2013. 